\title{
Different disaster characteristics of earth fissures and their influence factors in the Beijing plain
}

\author{
Zhao Long ${ }^{1}$, Luo Yong ${ }^{1}$, Li Yumei ${ }^{2}$, Tian Fang ${ }^{1}$, Liu He ${ }^{1}$, Lei Kunchao ${ }^{1}$, Sha Te ${ }^{1}$, Kong Xiangru ${ }^{1}$, and \\ Lu Menghan ${ }^{1}$ \\ ${ }^{1}$ Beijing Institute of Geo-Environment Monitoring, Beijing 100195, China \\ ${ }^{2}$ Development Research Center, China Earthquake Administration, Beijing 100045, China
}

Correspondence: Zhao Long (zszhaolong0123@yeah.net)

Published: 22 April 2020

\begin{abstract}
To analyze the generation of different ground fissure disasters, two typical ground fissures were selected. With geological survey and exploration data, the spatial characteristics of the Songzhuang and Gaoliying fissures were investigated. The different occurrence factors for the Songzhuang and Gaoliying fissures were analyzed based on geological structure and groundwater. The conclusions contain are as follows. The affected body of the Songzhuang fissure exhibits obvious tensile deformation, and it is not contact with buried faults. The fracture-affected body of the Gaoliying fissure shows obvious vertical dislocation and shear, and this is compounded with buried faults. The distribution characteristic of the Songzhuang fissure was controlled by the tectonics and the normal fault, while the buried fault not only control the distribution feature of the Gaoliying fissure but also controlled its deformation characteristic. A buried fault is the geological background for the formation of the Gaoliying fissure. The long-term exploitation of groundwater has caused the horizontal deformation of the soil and the rigid rotation of stratum in the subsidence edge. Both of them are the reason for the tensile deformation. Due to the activities of buried faults and differential subsidence in small areas, the affected bodies of the Gaoliying fissure showed vertical dislocation and shear deformation.
\end{abstract}

\section{Introduction}

Ground fissure is a kind of geological hazard which directly or indirectly reduces the environmental quality and endangers the development of human beings and the biosphere, with potential, slow-changing and instant-like characteristics (Holzer, 1984). The ground fissures in Beijing appeared after the Xingtai earthquake in 1965. Statistical results show that more than 40 ground fissures have been found in the Beijing plain area since the 1960s, and seven ground fissures are still developing rapidly in the plain area, as shown in recent investigations (Zhao et al., 2018b).

In the long-term investigation and monitoring of ground fissures, the author found that there are different manifestations of disaster bodies in Beijing plain area; one type is mainly horizontal tension, and the other type is mainly vertical dislocation. It was found by field investigation that the two types of manifestations were unrelated to the type of dis- aster, having obvious regional characteristics. So what factors influence this phenomenon, and what are the different genetic patterns? Do different genetic patterns have an influence on the future control work?

In this paper, the characteristics and influence factors for the disaster bodies of two ground fissures with typical disaster phenomena (Gaoliying ground fissure and Songzhuang ground fissure) are analyzed from the perspectives of regional stress fields, concealed faults and differential subsidence in detail.

\section{Ground fissure development characteristics}

\subsection{Surface distribution and disaster characteristics}

The Songzhuang ground fissure developed in the northeast of Tongzhou district, spreading in the northeastern direction and starting from Xiaozhong River in the south to Shuangbutou village, Gouqu village, Dapang village and Pingjiatuan 
village, with intermittent development and a total length of $8.7 \mathrm{~km}$. The Gaoliying fissure developed at the junction of Changping and Shunyi, spreading in the northeastern direction and extending from Baxian village in Changping district through Wenyu River to Xiwanglu village in Shunyi district, with intermittent development and a total length of $10 \mathrm{~km}$ (Fig. 1).

In order to fully reveal the different disaster characteristics of the two fissures, two areas with serious fissure disasters were selected for comparative analysis of the disaster characteristics of the wall and ground. The analysis results show that the Songzhuang ground fissures are mainly characterized by tensile failure. At the bottom of the wall, there are vertical cracks and high-angle inclined cracks that extend upward at high angles, and the ground exhibits obvious tensile deformation. In contrast, the damage caused by the fissure in the Gaoliying fissure is mainly characterized by vertical displacement and shear failure. At the bottom of the wall, oblique cracks are formed at a low (slow) angle, and the wall is twisted. There is a significant vertical shift on the ground (Fig. 2).

\subsection{Shallow profile characteristics}

The shallow structural characteristics of the two ground fissures are obtained by trenching, respectively. In the profile, Songzhuang ground fissures extend approximately upright, and the width of the fissure narrow gradually expands from top to bottom and then disappeared at the bottom, which looks like a trumpet. Its widest point is at more than $1 \mathrm{~m}$, and its narrowest point is at about $1 \mathrm{~cm}$. The attitude is approximately horizontal, and the lithology is mainly silty soil and silty clay, and there is no obvious dislocation on both sides of the ground fissure. The main crack is filled with a large number of secondary deposits whose moisture content is higher than that of soil on both sides, with an obvious phenomenon of hydrodynamic erosion. The Gaoliying fissure extends longitudinally inclined to the southeast with a dip angle of $80^{\circ}$, which is basically consistent with the attitude of the Huangzhuang-Gaoliying fault. A total of nine strata sets are revealed, which are artificial fill, clay powder, silty clay, silty sand and sandy silt. The strata staggered by the ground fissure (one side of the stratum relative decline is called the upper wall; the other side is called the lower wall) includes three layers of clayey silt, four layers of silt, five layers of clayey silt, six layers of medium sand and eight layers of silty clay, among which the maximum displacement is $1.24 \mathrm{~m}$ belonging to the three clayey silt layers. There are seven layers of sandy silt absented in the upper wall, and the thickness of five silt layers in the upper wall is less than that of the lower wall (Jia et al., 2007).

\section{Analysis of influencing factors}

A large number of research results show that earthquake, hidden faults and groundwater dynamic factors are the main factors affecting the formation and development of ground fissures in Beijing. In this section, the response of different factors to the characteristics of ground fissure disasters is systematically analyzed by using long-sequence monitoring data and synthesizing field investigation results.

\subsection{Regional stress}

Under the combined influence of subduction of the Pacific plate and northward migration of the Qinghai-Tibet block, the North China Plain is in an approximately east-west compressive stress field. The Nanyuan-Tongxian fault and Huangzhuang-Gaoliying fault developed in the Beijing plain and are northeast-trending distributed faults, which generate a dextral torsion by the compression of east-west-trending tectonic stress $(\mathrm{Xu}, 2012)$. Under the regional stress, the ground fissure that developed over the conceal fault possess the dextral deformation feature in Beijing. Therefore, the regional stress affects the deformation of ground fissure.

\subsection{Concealed fault}

The field investigation results show that the underlying Nanyuan-Tongxian fault has a certain controlling effect on the development of Songzhuang ground fissures because the Songzhuang ground fissures are concentrated in the upper wall of the Nanyuan-Tongxian fault and the dominant trend is northeastern, which is consistent with that of the NanyuanTongxian fault.

The latest active period of the Nanyuan-Tongxian fault was in the late Pleistocene and not the Holocene. The exploration results reveal that the Songzhuang ground fissures are developed in Holocene strata at a depth of $0-17 \mathrm{~m}$ and have no reconnecting compound relation with the NanyuanTongxian fault (Zhao et al., 2018a).

Based on the analysis of prospecting trench profile information and monitoring data, it is shown that the Songzhuang ground fissures are characterized by both horizontal tension and horizontal dextrality, while the Nanyuan-Tongxian fault is characterized by vertical stratum dislocation. The average vertical activity rate is $0.2 \mathrm{~mm} \mathrm{a}^{-1}$ in the latest active period, which was the late Pleistocene (Zhao et al., 2018b). Therefore, in terms of main deformation, there is a great difference between them.

The disaster bodies of ground fissures in Gaoliying are linearly distributed, and the influence range of ground fissures is relatively small. The strike of ground fissures is consistent with that of the Huangzhuang-Gaoliying fault (northern Qijia-Gaoliying section). The results of trench exploration reveal that the fissures in Gaoliying are reconnected with Huangzhuang-Gaoliying fault. In other words, the ground 

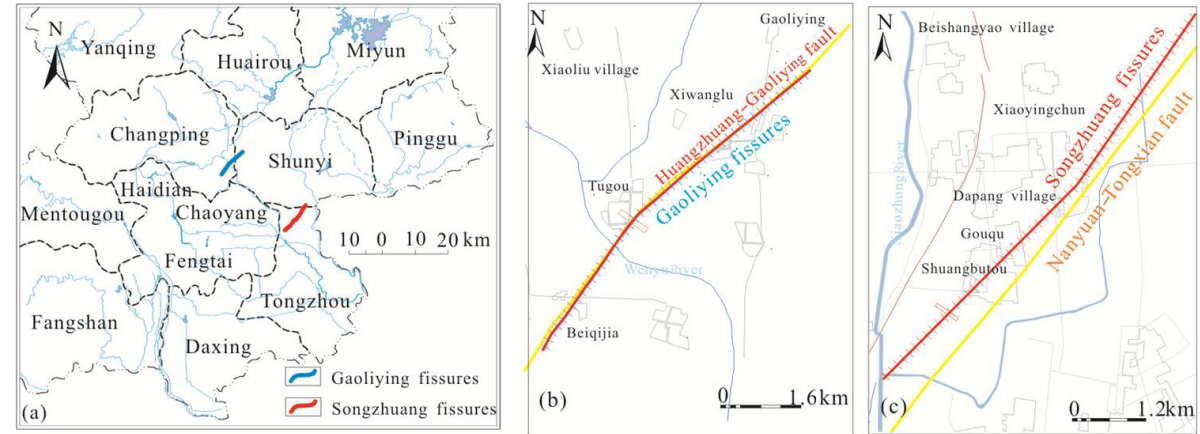

$\square$ Ground fissures $\square$ Trench $\square$ Fault

Figure 1. The location of Songzhuang ground fissures and Gaoliying ground fissures (a); work layout of Gaoliying fissures (b); work layout of Songzhuang fissures (c).
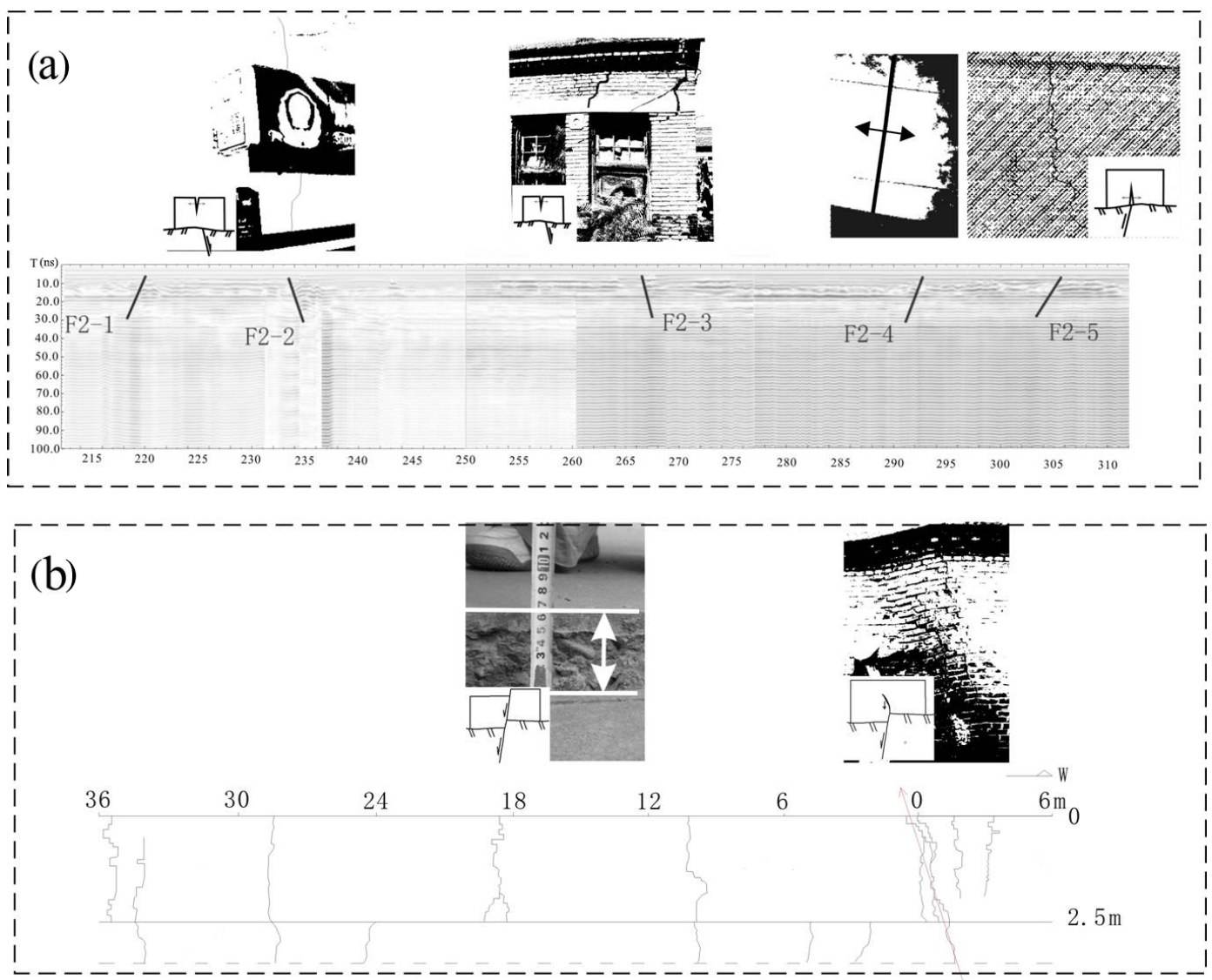

Figure 2. Hazard of Songzhuang ground fissures (a) and Gaoliying ground fissures (b). The photos in this figure are from Zhao et al. (2018b).

fissures in Gaoliying are the result of the extension and development of the Huangzhuang-Gaoliying fault and its surface performance.

From the monitoring data, it is known that vertical dislocation of ground fissures is the main deformation feature. The spatial distribution of ground fissures decreases in the southeast and rises in the northwest. The Huangzhuang-Gaoliying fault, a Holocene active fault, has the fault pattern in which the southeast disk descends, while the northwest disk rises and is a positive fault property. The results are relatively consistent from the perspective of main deformation characteristics.

The average vertical activity rate of the Holocene is known to be $0.10 \mathrm{~mm} \mathrm{a}^{-1}$ from the borehole data of the Huangzhuang-Gaoliying fault (northern Qijia-Gaoliying section) (Zhang et al., 2017). The average vertical activity 
rate of ground fissures is $8.1 \mathrm{~mm} \mathrm{a}^{-1}$ (2009-2017), as obtained from the ground fissure monitoring data. Obviously, the deformation rate of the two is at least 1 order of magnitude different. From the viewpoint of deformation rate, the deformation rate of Gaoliying ground fissures is much higher than that in the Huangzhuang-Gaoliying fault.

\subsection{Groundwater power}

A large number of scholars have shown that the ground subsidence caused by groundwater exploitation leading to local stress field changes is an important factor leading to the formation of ground fissures (Tian et al., 2017; Yang et al., 2014). The results of InSAR (interferometric synthetic aperture radar) monitoring in 2014 are shown in Fig. 3; the interpretation results were tested by level and GPS at a single point, and the maximum correlation coefficient is 0.889 . It can be seen that the two fissures both developed on the edge of the ground settlement funnel, where there is a significant differential settlement. As the sedimentation rate from $A$ to $A^{\prime}$ presents a trend of decreasing fluctuation and the deformation gradient is between positive and negative as shown in Fig. 3a, the Songzhuang ground fissures are developed in areas with a steep subsidence rate and large gradient of surface deformation. Figure $3 b$ shows that the sedimentation rate from $B$ to $B^{\prime}$ presents a trend of decreasing fluctuation, and the deformation gradient is between positive and negative, showing that the ground fissures in Gaoliying are also developed in the areas with a steep subsidence rate and large gradient of surface deformation.

The spatial distribution of ground subsidence and groundwater depression in the Beijing plain has a good consistency (Tian et al., 2017), so the two ground fissures are developed simultaneously at the edge of groundwater depression; that is, the groundwater affects the development of ground fissures to a certain extent.

The following points are specifically analyzed, firstly, as a vertical deformation of the soil layer caused by water level depression. The long-term continuous and concentrated exploitation of groundwater results in the differential compression of the strata from the mining center outward. The formation rigid will be reversed (Bouwer, 2010), and the tensile failure will be formed on the surface when the accumulated amount exceeds the tensile strength of the soil, as the tensile stress is concentrated and accumulated continuously at the edge of the settlement. Secondly, under the action of seepage, on the one hand, with the water flow velocity increasing, the loose fine particles in the dual-structure soil layer are washed, and a large number of fine sand particles are taken away, resulting in a change of the original stress state of the aquifer caused by a large number of voids in the aquifer (Yang et al., 2014). On the other hand, the horizontal compression of the aquifer occurs due to viscous dragging of the original aquifer skeleton (Helm, 1994). Based on the Darcy-Gersevanov generalized relation, combined with the volume permeability re- lationship (Eq. 2) and the osmotic force relationship (Eq. 3), the combined Eqs. (1), (2) and (3) can obtain Eq. (4), indicating relationships between the radial average flow velocity of solid particles, the osmotic force and the hydraulic gradient, and the horizontal compression of the soil in the aquifer.

$q=n\left(V_{\mathrm{w}}-V_{\mathrm{s}}\right)=k \frac{\partial h}{\partial r}$,

where $V_{\mathrm{s}}$ is the flow velocity of water, $V_{\mathrm{w}}$ is the flow velocity of water, $n$ is the aquifer porosity, $k$ is the aquifer permeability coefficient and $\frac{\partial h}{\partial r}$ is the radial hydraulic gradient.

$q_{b}=n V_{\mathrm{w}}+(1-n) V_{\mathrm{s}}$,

where $V_{\mathrm{s}}$ is the flow velocity of solid particles, $V_{\mathrm{w}}$ is the flow velocity of water and $q_{b}$ is the volume flow of pore water and solid particles passing through radial unit cross section in unit time.

$F_{b}=(\rho g / K) q_{b}$,

where $F_{b}$ is the osmotic force per unit volume, $\rho$ is the water density, $g$ is gravity acceleration and $K$ is the aquifer conductivity tensor.

$V_{\mathrm{s}}=\frac{F_{b}}{\rho g / K}-k \frac{\partial h}{\partial r}$,

where $V_{\mathrm{s}}$ is the flow velocity of solid particles, $F_{b}$ is the osmotic force per unit volume, $\rho$ is the water density, $g$ is gravity acceleration, $K$ is the aquifer conductivity tensor, $k$ is the aquifer permeability coefficient and $\frac{\partial h}{\partial r}$ is the radial hydraulic gradient.

The horizontal movement rate of soil particles is affected by the permeability coefficient and hydraulic gradient as shown in Eq. (4); the horizontal movement rate of soil particles is different because of the complexity of the groundwater system. Because of the differential horizontal movement rate, tension stress is formed in the soil layer, and the accumulation of tension stress is released in the weak place of the ground surface, which leads to the appearance of the tension failure of ground fissures.

\section{Conclusions}

Songzhuang ground fissures and Gaoliying ground fissures both developed in the Beijing plain area, but their manifestations of shallow-section characteristics are quite different. There is obvious stretching deformation in the disaster bodies of Songzhuang ground fissures; the fissures extend vertically near the surface in the shallow, with a small extension depth, and the fissures are not reconnected with concealed faults. The disaster bodies of ground fissures in Gaoliying are characterized by significant vertical dislocation and shear failure. Ground fissures extend from the surface in the shallow section with a large extension depth and dislocation of strata, 

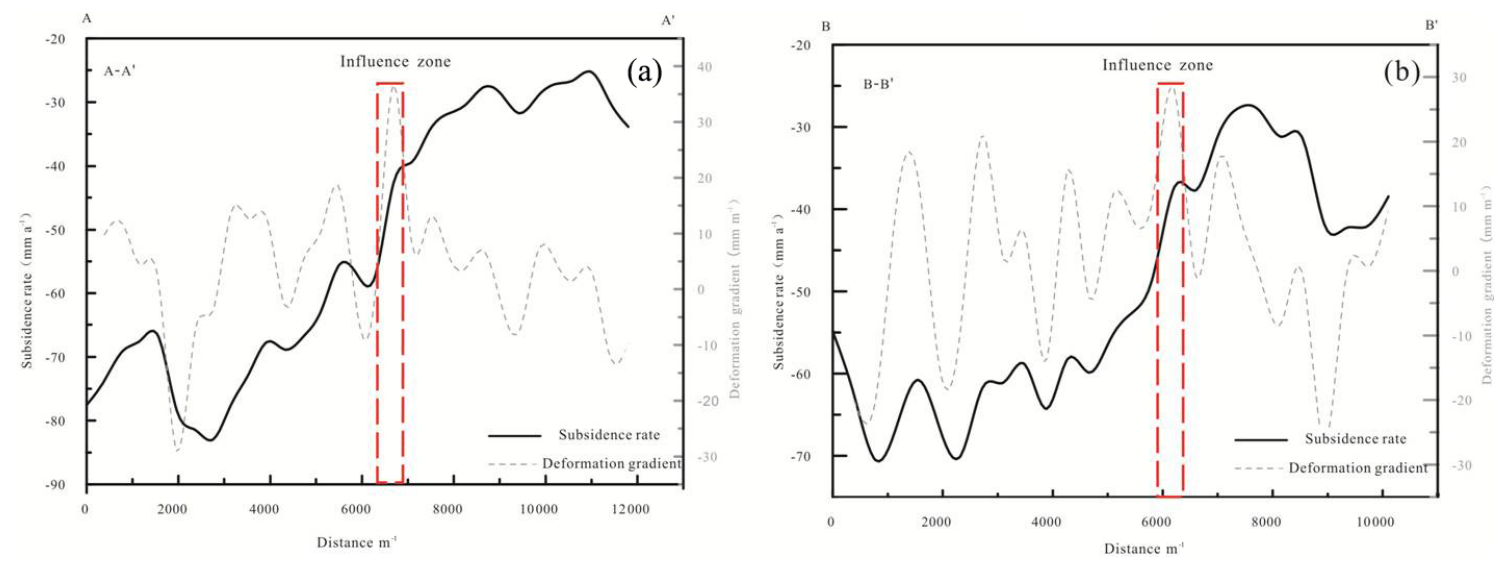

Figure 3. Rate of land subsidence measured by InSAR in the ground fissures and deformation characteristics.

and the fissures are reconnected with concealed faults in the deep section.

The formation of ground fissures in Songzhuang is controlled by both internal and external dynamic geological processes. Important fissure initiation conditions for the development of ground fissures in Songzhuang are provided by the ground fracture zones formed by regional stress field and normal fault dragging. The inducing condition for the development of Songzhuang ground fissures is the long-term sustained and concentrated exploitation of groundwater, resulting in differential horizontal movement of soil particles under seepage as well as the rigid inversion of strata at the subsidence margin. This is the main reason for the horizontal tension deformation of the affected bodies.

The formation of ground fissures in Gaoliying is controlled by both internal and external dynamic geological processes. Concealed faults provide an important geological background for the formation of ground fissures in Gaoliying. The one inducing condition for the development of Gaoliying ground fissures is the long-term sustained and concentrated exploitation of groundwater, resulting in the differential horizontal movement of soil particles under seepage as well as the rigid inversion of strata at the subsidence margin. This is the main reason for the horizontal tension deformation of the affected bodies. The other inducing condition for the development of ground fissures in Gaoliying is the differential subsidence and concealed fault activity in a small area. These are important reasons for the vertical dislocation and shear deformation of the disaster bodies.

Data availability. The data of this paper can not publicly accessible. This paper aims analyze the phenomenon of difference deformation of ground fissures in the Beijing plain. The trench and InSAR data were used. The trench image cites other published papers. Due to copyright, it is not possible to provide the image. The InSAR data related to Beijing was confirmed in a secret document.
Author contributions. ST, KX and LM designed and preformed the field investigation; LY, LK and TF preformed the analysis and computation job of SAR. LY collected the references and mapped the figure.

Competing interests. The authors declare that they have no conflict of interest.

Special issue statement. This article is part of the special issue "TISOLS: the Tenth International Symposium On Land Subsidence - living with subsidence". It is a result of the Tenth International Symposium on Land Subsidence, Delft, the Netherlands, 17-21 May 2021.

Acknowledgements. Thanks go to my institute and all colleagues for their efforts to finish the results of this report.

Financial support. This research has been supported by the Beijing Council of Science and Technology (grant no. Z191100001419007).

\section{References}

Bouwer, H.: Land subsidence and cracking due to groundwater depletion, Groundwater, 15, 358-364, 2010.

Helm, D. C.: Horizontal aquifer movement in a Theis Thiem confined system, Water Resour. Res., 30, 953-964, https://doi.org/10.1029/94WR00030, 1994.

Holzer, T. L.: Ground failure induced by groundwater withdrawal from unconsolidated sediments, Geological Society of America Reviews in Engineering Geology VI, 67-105, 1984.

Tian, F., Luo, Y., Zhou, Y., Li, Y., Kou, W. J., Jiang, Y., and Wang, $\mathrm{R}$ : Contrastive analysis of spatial $\sim$ temporal evolution between land subsidence and groundwater exploitation in Beijing, South 
to North Water Transfers and Water Science and Technology, 15, 163-0-169, 2017.

$\mathrm{Xu}$, J. S.: Study on the formation mechanism of ground fissures in North China Epicontinental Basin, Chang' an University, 2012.

Yang, W. M., Zhang, Y. S., Huang, X., and Qiu, Z. L.: Formation mechanism and evolution of the Caohe River earth fissure in the Bailou Village of Xushui county, Hydrogeol. Eng. Geol., 41, 122-128, 2014.

Zhang, L., Zhang, X. L., Bai, L. Y., Yang, T. S., Cai, X. M., and Liang, Y. N.: Activity study and disaster effect analysis of the north section of Huangzhuang Gaoliying fault in Beijing, J. Geomech., 23, 548-557, 2017.
Zhao, L., Li, Y. M., Chui, W. J., Luo, Y.,Zhang, Y. Q., Tian, F., Lei, K. C., Qiao, L., Sha, T., Tian, M. Z., Wang, X. H., Kong, X. R., Liu, H., and Qi, M. H.: Disaster characteristics and influence factors for Songzhuang, earth fissure in Beijing, J. Eng. Geol., 6, 1600-1610, 2018a.

Zhao, L., Luo, Y., Wu, Z. K., Luo, Y.,Zhang, Y. Q., Tian, F., Lei, K. C., Sha, T., Tian, M. Z., Wang, X. H., Kong, X. R., Liu, H., and Qi, M. H.: High accuracy $(1: 50,000)$ investigation report of ground subsidence and ground fissure in Beijing plain area, Beijing Institute of Hydrogeology and Engineering Geology, $2018 \mathrm{~b}$. 